\title{
Porosity of Silica Monoliths with Tailored Mesopores of Ink-Bottle Shape Determined by Nitrogen Adsorption and Positron Annihilation Lifetime Spectroscopy
}

\author{
A. Sienkiewicz ${ }^{a}$, A. Kierys ${ }^{a}$, M. Gorgol ${ }^{b}$ And R. Zaleski ${ }^{b, *}$ \\ ${ }^{a}$ M. Curie-Skłodowska University, Faculty of Chemistry, Department of Adsorption, \\ pl. M. Curie-Skłodowskiej 3, 20-031 Lublin, Poland \\ ${ }^{b}$ M. Curie-Skłodowska University, Institute of Physics, Department of Nuclear Methods, \\ pl. M. Curie-Skłodowskiej 1, 20-031 Lublin, Poland
}

\begin{abstract}
The comparison of pore size distributions obtained with the use of two porosimetric methods: low temperature nitrogen sorption (LN2) and positron annihilation lifetime spectroscopy (PALS), was performed for porous silica monoliths. Four investigated samples were prepared under various synthesis conditions. Nitrogen sorption showed the presence of bottle-shaped pores in all investigated samples. In addition, it seems that the presence of methanol during synthesis influences porosity to a greater extent than organic additives. Quite good agreement between the LN2 and PALS results was observed only for the silica monolith synthesized with $\beta$-cyclodextrins as pore directing agent. The biggest discrepancy in the results obtained from these two techniques was observed for the silica gel synthesized with no additives. The origin of such discrepancies, taking into account the shape of pore size distribution and deficiencies of data analysis techniques, is discussed.
\end{abstract}

DOI: 10.12693/APhysPolA.132.1568

PACS/topics: 81.05.Rm, 68.43.-h, 81.70.-q, 78.70.Bj, 36.10.Dr

\section{Introduction}

The silica gel is a well-known and widely studied material. It occurs in various natural and artificial shapes and forms [1-5]. Due to its adsorptive properties, heat resistance and environmental friendly character the most interesting silica species are the porous one. During synthesis of silica gel, silica precursor e.g. tetramethyl orthosilicate, hydrolyzes and condenses to form the network of strong covalent silica-oxygen bonds [6]. The condensation process spontaneously results in creation of porous structure. The shape and arrangement of pores can be successfully tailored by introduction of certain chemical compounds (i.e. surfactants) or more complexed matrices [7] into silica precursor transformation environment. Silica species surround chemical entities present in their vicinity, and after their removal in the process of extraction or calcination, $\mathrm{SiO}_{2}$ with voids is obtained.

The goal of the presented paper was to test the agreement between the results of the two very different porosimetric methods based on: low temperature nitrogen adsorption-desorption and annihilation lifetimes of orthopositronium $(o-\mathrm{PS})$ in silica monoliths obtained with different nanoscale pore directing agents (methanol, $\beta$ cyclodextrins and polystyrene nanobeads).

\section{Experimental \\ 2.1. Materials}

The silica gel (SG) was obtained by mixing $5 \mathrm{ml}$ of tetramethyl orthosilicate (TMOS, Sigma-Aldrich) with

\footnotetext{
*corresponding author; e-mail: radek@zaleski.umcs.pl
}

$7.5 \mathrm{ml}$ of $0.06 \mathrm{M} \mathrm{NaOH}$ (POCH, Poland) aqueous solution. After gelation (shorter than $3 \mathrm{~min}$ ) the sample was stored for 3 days in a closed container at room temperature. Next, SG was dried at $80^{\circ} \mathrm{C}$ for $8 \mathrm{~h}$ and calcined in air at $550^{\circ} \mathrm{C}$ for $6 \mathrm{~h}$, after an initial rate of temperature increase of $1{ }^{\circ} \mathrm{C} / \mathrm{min}$. The sample named SG-CD was prepared in a similar way, but $0.3 \mathrm{~g}$ of $\beta$-cyclodextrin (Sigma-Aldrich) were dissolved in it, prior to pouring basic aqueous solution into organic silica precursor.

Amounts of chemicals to obtain silica monolith named SG-M were used as described in [8], i.e. $5 \mathrm{ml}$ of TMOS was mixed with $5 \mathrm{ml}$ of methanol (POCH, Poland) and $2.5 \mathrm{ml}$ of $0.06 \mathrm{M} \mathrm{NaOH}$. Obtained wet silica gel was annealed for $24 \mathrm{~h}$ and subsequently transferred to a container with methanol (approximately $20 \mathrm{ml}$ ). Small portions (ca. $2 \mathrm{ml}$ ) of redistilled water were added during next three day period (up to $60 \mathrm{ml}$ of water content). Then, the silica gel was transferred from the methanolic solution to redistilled water and kept tightly closed at room temperature for $72 \mathrm{~h}$. Subsequently sample was dried at $80^{\circ} \mathrm{C}$ for $12 \mathrm{~h}$ and calcined at $550^{\circ} \mathrm{C}$ for $4 \mathrm{~h}$ in air. The rate of temperature increase was $1^{\circ} \mathrm{C} / \mathrm{min}$ in both cases. The same procedure was used for the SG-ML synthesis, except that $0.1 \mathrm{~g}$ of $1 \%$ polystyrene spheres $(22 \mathrm{~nm})$ solution (Nanosphere ${ }^{\mathrm{TM}}$ size standard, Thermo Scientific) was added to the methanol mixed with TMOS and $0.06 \mathrm{M} \mathrm{NaOH}$.

Every reagent used in the synthesis was used as received. All materials under study were obtained as transparent monoliths with approximate mass of $2 \mathrm{~g}$.

\subsection{Methods}

Low temperature (at $-196^{\circ} \mathrm{C}$ ) nitrogen adsorptiondesorption experiment (LN2) carried out with a ASAP 
2405 (volumetric adsorption analyser) manufactured by Micromeritics, provided data for calculation of BET specific surface area [9] of the samples. The total pore volumes were estimated from a single point adsorption at $p / p_{0}=0.995$. The pore size distributions (PSD) were obtained from BJH procedure [10].

In order to perform PALS measurement, a standard fast-slow delayed coincidence spectrometer was used. An investigated sample, was surrounding the ${ }^{22} \mathrm{Na}$ radioactive source with the activity of $c a .0 .2 \mathrm{MBq}$. The $\gamma$ quanta accompanying positron creation (start) and positron/positronium annihilation (stop) were collected by two scintillation detectors equipped with $\mathrm{BaF}_{2}$ scintillators. The time intervals between start and stop events were determined by a time-to-amplitude converter within the time range of $2 \mu \mathrm{s}$. This allowed to measure lifetimes of positronium annihilating even in large mesopores. The resolution curve was approximated by two Gaussians with the full-width-at-half-maximum (FWHM) of ca. 290 and 440 ps and the intensity ratio 20:1.

During first measurement series, all investigated samples were kept in the pressure less than $10^{-4} \mathrm{~Pa}$, obtained with the use of a turbomolecular pump. In order to verify presence of closed pores in SG and SG-M, these two samples were additionally investigated in oxygen under pressure of $1 \mathrm{~atm}$. This was achieved with the use of gas application system, attached to the vacuum supply system. All measurements were carried out at room temperature.

The pore sizes corresponding to lifetimes were calculated using the ETE model [11] implemented in EELViS routine [12] assuming $\Delta=0.18 \mathrm{~nm}$ and pores with the shape of infinite cylinders. PSDs were calculated from the $o$-Ps lifetime distribution using the model described in Ref. [13].

\section{Results and discussion}

The isotherms of all investigated materials (Fig. 1) are of type IV with $\mathrm{H} 2$ type hysteresis, as defined by the IUPAC classification [14]. The loop of hysteresis is asymmetric in shape and is typical for materials of highly interconnected pores. In many cases the larger pores (the main cavities) are connected via smaller one which act as a neck. In such complex pore system the mechanism of desorption may involve the pore blocking and cavitation effects which are widely presented in the literature of the subject [15-17]. The analysis adsorption branch of $\mathrm{N}_{2}$ isotherm gives information concerning the main pore/cavity size distribution, whereas the distribution of neck sizes (smaller pores) can be obtained from an analysis of the desorption branch of $\mathrm{N}_{2}$ isotherm [17].

The PSDs obtained by BJH method from the adsorption and desorption branches of isotherms are presented in Fig. 2, and the pore diameters at the peaks of PSD are given in Table I. The analysis of these parameters indicate that introduction of $\beta$-cyclodextrin does not have significant impact on them since they are almost identical for SG and SG-CD samples. Surprisingly, the silica

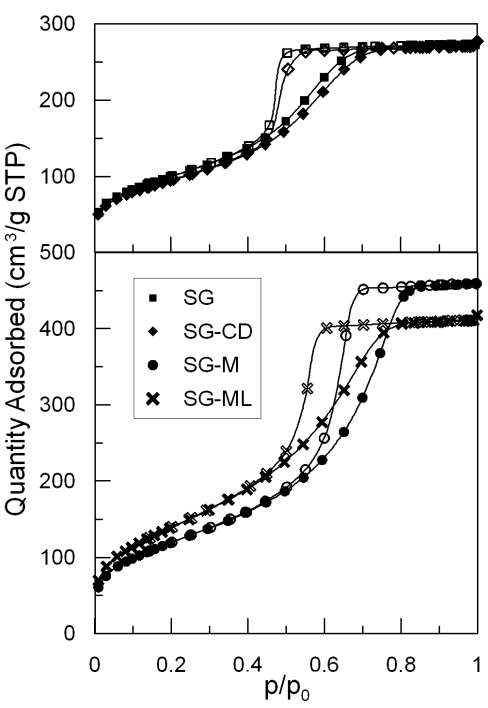

Fig. 1. Nitrogen adsorption/desorption isotherms at $196{ }^{\circ} \mathrm{C}$ for the samples under study. Adsorption - full symbols, desorption - empty symbols.

gel produced by the use of polystyrene spheres (SG-ML) possess slightly smaller pores and the total pore volume than that produced without them (SG-M). On the other hand, the specific surface area increases by about $17 \%$ for sample SG-ML and it is the largest of all samples. The lack of the significant differences between parameters characterizing porosity derived from LN2 despite different procedure of synthesis, encourages us to employ PALS to investigate these samples.

TABLE I

Parameters characterizing porosity of the samples under study obtained from nitrogen isotherms: the specific surface area $\left(S_{\mathrm{BET}}\right)$, the total pore volume $\left(V_{\mathrm{LN} 2}\right)$ and the pore diameter at the peak of PSD derived from the desorption $\left(D_{\mathrm{BJH}}^{\text {des }}\right)$ and adsorption $\left(D_{\mathrm{BJH}}^{a d s}\right)$ branch of $\mathrm{N}_{2}$ isotherm.

\begin{tabular}{c|c|c|c|c}
\hline \hline Sample & $\begin{array}{c}S_{\mathrm{BET}} \\
{\left[\mathrm{m}^{2} / \mathrm{g}\right]}\end{array}$ & $\begin{array}{c}V_{\mathrm{LN} 2} \\
{\left[\mathrm{~cm}^{3} / \mathrm{g}\right]}\end{array}$ & $\begin{array}{c}D_{\mathrm{BJH}}^{\text {des }} \\
{[\mathrm{nm}]}\end{array}$ & $\begin{array}{c}D_{\mathrm{BJH}}^{\text {ads }} \\
{[\mathrm{nm}]}\end{array}$ \\
\hline SG & 368 & 0.42 & 3.8 & 4.3 \\
SG-CD & 348 & 0.43 & 3.7 & 4.8 \\
SG-M & 439 & 0.71 & 5.5 & 7.6 \\
SG-ML & 516 & 0.65 & 4.3 & 5.6
\end{tabular}

The para-positronium (1), free positron (2) and three $o$-Ps (3-5) components are sufficient to obtain fit of $\chi^{2}=1.02-1.05$ using LT programme [18] (Table II). The shortest-lived o-Ps component (3) origins from the bulk silica. Its intensity is surprisingly small and indicates higher porosity than expected from the results of nitrogen adsorption. Its lifetime is relatively large for a silica and suggests rather loose structure, especially for SG$\mathrm{M}$ and SG-ML. The medium-lived o-Ps component (4) has the lifetime characteristic for micropores of size $0.7-$ $1.4 \mathrm{~nm}$. However, this value is only approximate due to 
very low $I_{4}$, which testifies about negligible microporosity. The intensity of the long-lived $o$-Ps component (5), which originates from mesopores, is as large as observed for materials with twice larger pore volume and surface area and pores of comparable size [19]. The discussion of this component and its comparison with results of nitrogen adsorption requires to take into account all three parameters $\left(I_{5}, \tau_{5}\right.$ and $\left.\sigma_{5}\right)$ and their transformation to PSDs by means of positron porosimetry [20].

\section{TABLE II}

Intensities, lifetimes and dispersion of $o$-Ps components for the samples under study.

\begin{tabular}{c|c|c|c|c|c|c|c}
\hline \hline Sample & $I_{3}[\%]$ & $\tau_{3}[\mathrm{~ns}]$ & $I_{4}[\%]$ & $\tau_{4}[\mathrm{~ns}]$ & $I_{5}[\%]$ & $\tau_{5}[\mathrm{~ns}]$ & $\sigma_{5}[\mathrm{~ns}]$ \\
\hline SG & $3.6(2)$ & $1.8(2)$ & $0.8(2)$ & $14(1)$ & $32.6(2)$ & $104(2)$ & $23(7)$ \\
SG-CD & $2.9(3)$ & $1.6(2)$ & $0.9(2)$ & $6(1)$ & $36.9(3)$ & $72(1)$ & $19(4)$ \\
SG-M & $2.8(2)$ & $2.4(2)$ & $0.7(1)$ & $15(1)$ & $29.8(2)$ & $97(2)$ & $24(6)$ \\
SG-ML & $2.0(2)$ & $2.6(3)$ & $0.5(2)$ & $12(1)$ & $31.1(3)$ & $87(2)$ & $25(7)$
\end{tabular}

The PSDs were calculated from the lognormal lifetime distributions obtained using LT and form the ones from MELT [21], which are not burdened with assumptions concerning the shape of distribution. They were compared to the PSDs obtained from BJH procedure applied to both nitrogen adsorption and desorption isotherms (Fig. 2). A good agreement between the results of both measurement techniques (NL2 and PALS) and various methods (LT and MELT) of data analysis was obtained only for SG-CD. Greatly surprising is that SG exhibits the greatest discrepancy between the results of positron and nitrogen porosimetry although the adsorption/desorption isotherms are almost identical for SG and SG-CD. Such shift towards greater lifetime would be possible if pore wall in SG has much lower electron density than normal silica. This would decrease the probability of pick-off annihilation of $o$-Ps, which is represented in the ETE model by the $\Delta$ parameter. However, $\Delta=0.13 \mathrm{~nm}$ is required to obtain reasonable agreement with nitrogen adsorption results. Such value is even lower than in polymer porous materials [7]. Also similar value of $\tau_{3}$, which reflects the density of the silica, in both SG and SG-CD do not support this hypothesis. Thus, this explanation is hardly reliable. Alternatively, a large group of closed pores, which are detected by PALS but not by LN2, can be present in the material. On the other hand, both SG$\mathrm{M}$ and SG-ML show the agreement between LN2 and PALS similar to SG-CD if the results of analysis by LT only are taken into account. This result is not reproduced by the distribution obtained from MELT. Instead, a bimodal PSD is found for both SG-M and SG-ML materials. It seems to be a consequence of the tendency of MELT to split wide lifetime distributions [22]. Most likely, this problem occurs, when PSD is wide and asymmetric (i.e. it has a tail on the side of small sizes). The maxima of both peaks are nearly at the same D in SG$\mathrm{M}$ and SG-ML, but the ratio of their height reflect the difference of pore size between these samples found by ni- trogen adsorption. Another possible explanation is that $o$-Ps is trapped preferably in two kinds of not interconnected pores of different size.

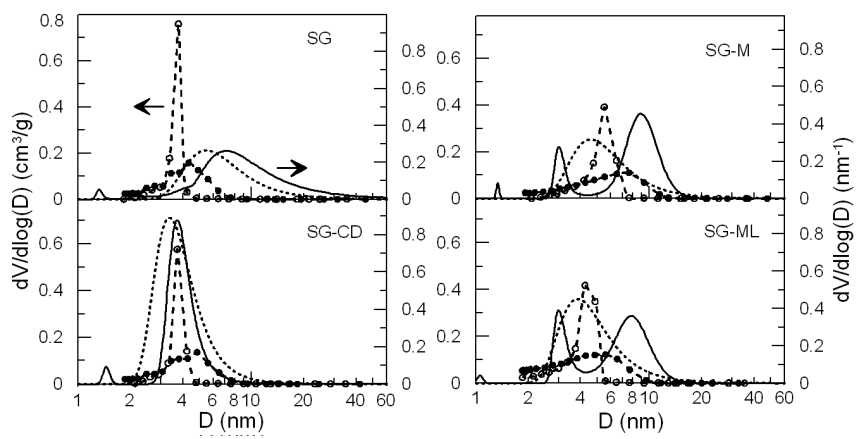

Fig. 2. Pore size distributions calculated from the $o$-Ps lifetime distributions obtained by LT (dotted line) and MELT (solid line) compared to PSDs from the nitrogen adsorption (dashed line, full symbols) and desorption (dashed line, empty symbols) isotherm using the BJH method.

The measurements in oxygen atmosphere were performed for SG and SG-M to verify whether closed pores are present in these materials. In the presence of $\mathrm{O}_{2} o$-Ps trapped in open pores undergoes quenching, which shortens its lifetime [23]. This shortening depends on partial pressure of oxygen. Thus, it will differ in air and pure oxygen under $1 \mathrm{~atm}$ (Fig. 3). However, oxygen cannot enter closed pores and the lifetime of $o$-Ps should remain unchanged there. In consequence, for closed pores of a particular size, in principle, the same lifetime would be observed in vacuum, air, or oxygen. It would be either specific for these pores in vacuum or for pores filled by air, if atmospheric gases have been trapped inside pores during a synthesis.
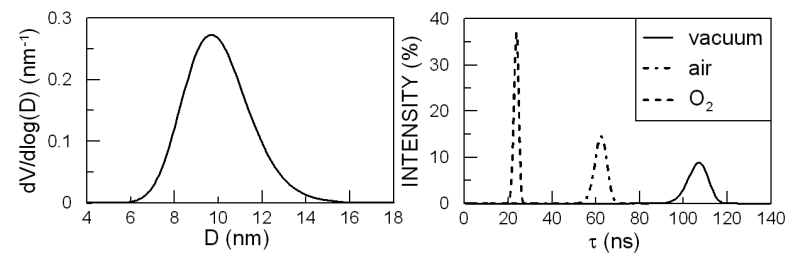

Fig. 3. Hypothetical pore size distribution and o-Ps lifetime distributions expected for it in vacuum, atmospheric air and oxygen under 1 atm.

The lifetime distributions measured in vacuum and oxygen (Fig. 4) do not overlap for any $\tau$ value. Moreover, no lifetime above $40 \mathrm{~ns}$ (corresponding to $D=2.4 \mathrm{~nm}$ in vacuum) is observed. Therefore the hypothesis of presence of closed pores is not supported. In addition, the PSDs for the results obtained in oxygen were calculated using the modified ETE model, which takes quenching by oxygen, both gaseous and adsorbed on pore walls, with rate $0.02 \mathrm{~ns}^{-1}$ into account [24]. The results confirm the PSD obtained for SG in vacuum with an exceptionally 
good accuracy. The comparison of the PSDs of SG-M confirms that the bimodal distribution is most likely not reliable.
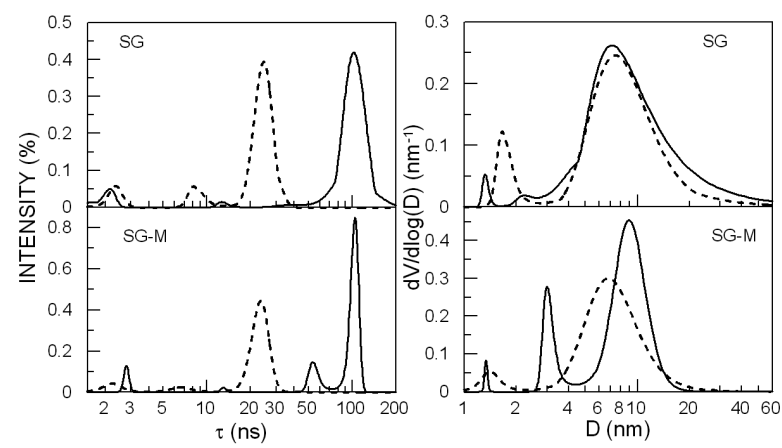

Fig. 4. Lifetime distributions and PSDs derived from spectra measured in high vacuum (solid line) and oxygen atmosphere (dashed line).

\section{Conclusions}

The low temperature adsorption-desorption nitrogen measurements indicate that the addition of organic additives (i.e. $\beta$-cyclodextrin or polystyrene spheres) does not significantly influence the porosity of the final silica gels, and consequently they are similar to silicas produced without additives. On the other hand, it is clear that transformation of silica precursor (under basic condition) in the presence of methanol, favours the silica gel production of larger specific surface area and the total pore volume. Thus, it may be concluded that methanol act as the efficient agent for pore forming.

The PALS measurements show a satisfactory agreement with the LN2 results for the SG-CD sample only. In the case of SG-M and SG-ML the problem lies most likely in the shape of PSDs. They are clearly different from lognormal, which is inherited from the methods of PALS data analysis. Both LT and MELT methods show tendency to represent their results in the form of one or more lognormal distributions. The greater number of degrees of freedom in MELT causes that it splits PSDs to bimodal distributions. Much more difficult is finding the origin of the discrepancy between the LN2 and PALS characterization of the porosity of SG. It cannot be explained by the presence of the closed pores since contribution from closed pores is negligibly small as indicated by the measurements in the oxygen atmosphere. Thus, the further studies on the molecular structure of these silica gel monoliths are required to understand the origin of the differences in the results. Also, it seems to be profitable to obtain information concerning the density and microporosity of the studied silica. Another possibility is that SG has the anomalous coefficient of thermal expansion, which makes the PSDs obtained with the use of two porosimetric methods: LN2 at $-196^{\circ} \mathrm{C}$ and PALS at $22^{\circ} \mathrm{C}$ incomparable. Therefore, a PALS measurement as a function of temperature is a promising way to find the origin of discrepancies. Such measurement can provide additional information even if the discrepancies are not directly related to the coefficient of thermal expansion.

\section{References}

[1] R. Ragni, S. Cicco, D. Vona, G. Leone, G.M. Farinola, J. Mater. Res. 32, 279 (2017).

[2] C.T. Kresge, M.E. Leonowicz, W.J. Roth, J.C. Vartuli, J.S. Beck, Nature 359, 710 (1992).

[3] D.Y. Zhao, J.L. Feng, Q.S. Huo, N. Melosh, G.H. Fredrickson, B.F. Chmelka, G.D. Stucky, Science 279, 548 (1998).

[4] C. Gerardin, J. Reboul, M. Bonne, B. Lebeau, Chem. Soc. Rev. 42, 4217 (2013).

[5] A. Kierys, M. Dziadosz, J. Goworek, J. Coll. Interface Sci. 349, 361 (2010).

[6] H.E. Bergna, Adv. Chem. Ser. 234, 1 (1994).

[7] M. Gorgol, M. Tydda, A. Kierys, R. Zaleski, Micropor. Mesopor. Mater. 163, 276 (2012).

[8] C.W. Clavier, D.L. Rodman, J.F. Sinski, L.R. Allain, H.J. Im, Y. Yang, J.C. Clark, Z.L. Xue, J. Mater. Chem. 15, 2356 (2005).

[9] S. Brunauer, P.H. Emmett, E. Teller, J. Am. Chem. Soc. 60, 309 (1938).

[10] E.P. Barrett, L.G. Joyner, P.P. Halenda, J. Am. Chem. Soc. 73, 373 (1951).

[11] T. Goworek, K. Ciesielski, B. Jasinska, J. Wawryszczuk, Chem. Phys. 230, 305 (1998).

[12] R. Zaleski, EELViS, July 13, 2017.

[13] J. Goworek, R. Zaleski, W. Buda, A. Kierys, Appl. Surf. Sci. 256, 5316 (2010).

[14] J. Rouquerol, D. Avnir, C.W. Fairbridge, D.H. Everett, J.H. Haynes, N. Pernicone, J.D.F. Ramsay, K.S.W. Sing, K.K. Unger, Pure Appl. Chem. 66, 1739 (1994).

[15] M. Thommes, B. Smarsly, M. Groenewolt, P.I. Ravikovitch, A.V. Neimark, Langmuir 22, 756 (2006).

[16] C. Reichenbach, G. Kalies, D. Enke, D. Klank, Langmuir 27, 10699 (2011)

[17] M. Thommes, Chem. Ing. Tech. 82, 1059 (2010).

[18] J. Kansy, Nucl. Instrum. Methods Phys. Res. A 374, 235 (1996).

[19] R. Zaleski, M. Gorgol, A. Błazewicz, A. Kierys, J. Goworek, J. Phys. Conf. Series 618, 012040 (2015).

[20] R. Zaleski, Nukleonika 60, 795 (2015).

[21] A. Shukla, M. Peter, L. Hoffmann, Nucl. Instrum. Methods Phys. Res. A 335, 310 (1993).

[22] R. Zaleski, Acta Phys. Pol. A 110, 729 (2006).

[23] Y. Zhou, W. Mao, Q. Li, J. Wang, C. He, Chem. Phys. 459, 81 (2015).

[24] R. Zaleski, M. Sokół, Mater. Sci. Forum 666, 123 (2011). 